\title{
Sero-molecular survey on Toxoplasma gondii infection among drug addicted and non-addicted individuals: a case-control study
}

Majid Sharifzadeh ${ }^{1}$, Hassan Rezanezhad ${ }^{1,2^{*}}$, Kavous Solhjoo ${ }^{1,2}$, Zahra Kargar Jahromi², Enayatollah Shadmand ${ }^{1}$, Saeed Shahabi ${ }^{3}$ and Ali Taghipour ${ }^{2}$

\begin{abstract}
Background: Up to now, epidemiological studies on the prevalence of Toxoplasma gondii infection among drug addicted individuals have been rarely performed. By designing an age and sex matched case-control study, we sought to determine the prevalence and associated factors with T. gondii infection in these population using serological and molecular techniques.

Methods: One hundred and thirty-seven drug addicted individuals and 141 healthy subjects were enrolled in this study. Informed consent as well as a standard questionnaire were obtained from all subjects participating. Blood samples were collected from each participant and the serum was screened for anti-Toxoplasma antibodies (IgG and IgM). PCR assay was performed using the primer pair targeting the RE and GRA6 genes of T. gondii. Then, PCR products were sequenced to determine genotype.

Results: The seroprevalence of T. gondii infection based on IgG titer was 34.3\% in case and $9.9 \%$ in the control groups, revealing a statistically significant difference $(\mathrm{OR}=4.37 ; 95 \% \mathrm{Cl}=2.46-9.12 ; \mathrm{P}=0.001)$. After analyzing the variables studied through the questionnaire, age was the only significantly factor associated with the anti-T. gondii lgG antibody in case group. Considering PCR assays with RE genomic target, the prevalence of T. gondii infection was 5.1\% in the case and 3.5\% in control groups which the difference was no statistically significant $(\mathrm{OR}=1.46 ; 95 \% \mathrm{Cl}=0.45-$ 4.73; $P=0.521$ ). Subsequently, all sequenced samples were genotype \#1 using the GRA6 genomic target.

Conclusions: T. gondii exposure is relatively high among drug addicted individuals in Iran, and there is a need for health policymakers and researchers to establish enlightenment and prevention programs for these population at risk of infection.
\end{abstract}

Keywords: Toxoplasmosis, Drug addicted individuals, Seroprevalence, Molecular prevalence

*Correspondence: rezasiv@gmail.com

${ }^{1}$ Department of Medical Parasitology and Mycology, School of Medicine,

Jahrom University of Medical Sciences, Jahrom, Iran

Full list of author information is available at the end of the article

\section{Background}

Toxoplasma gondii (T. gondii), a cosmopolitan intracellular protozoan belonging to the phylum Apicomplexa, is an opportunistic pathogen that infects humans and a wide range of warm-blooded animals, including livestock, birds, rodents, and aquatic mammals $[1,2]$. According to published literatures, this zoonotic parasite 
affects approximately one-third of the world's population, especially in communities with low socioeconomic level in many developing countries $[3,4]$. The life cycle of $T$. gondii consists of the felids (definitive hosts) and warmblooded vertebrates (intermediate hosts) [5], and pollution of environmental resources occurs only by the felids via shedding oocysts $[6,7]$.

Human toxoplasmosis occurs mostly via the intake of undercooked or raw meat products infected with tissue cysts [8], or by ingestion of soil, water, or vegetables infected with sporulated oocysts [9]. Moreover, T. gondii can be passed through transplacental transmission, blood transfusions, and organ transplantation [10-12]. T. gondii infection is usually asymptomatic in immunocompetent individuals, but the parasite may induce neurological and ocular disorders in fetuses and immunocompromised patients [13, 14]. Moreover, numerous studies have suggested that this protozoan plays a potential role in increasing the incidence of psychiatric diseases (e.g. schizophrenia, autism, and major depression), suicide, traffic accidents, and addiction [15-19].

Narcotic drugs are serious public health threat in many countries, notably in Asia (Iran, Afghanistan, Pakistan, and India) [20, 21]. Many research studies have shown that narcotic drug addiction can disrupt the immune system and provides suitable conditions for infectious diseases [22-24]. In this regard, narcotic drugs addiction and $T$. gondii infection are endemic in different parts of Iran. According to published meta-analysis studies, the seroprevalence of T. gondii in the general population [25], pregnant women [26], and immunocompetent individuals [27] has been reported as $39.3 \%, 41 \%$ and $50.01 \%$ in Iran, respectively. To the best of our knowledge, very few studies have been performed on the status of T. gondii infection in drug addicted individuals as a high-risk population [28, 29]. Therefore, the present case-control study was conducted to assess the prevalence, sociodemographic, and risk factors associated with this infection in drug addicted and non-addicted individuals using both serologic and molecular techniques.

\section{Methods}

\section{Study population and sample collection}

The current case-control study obtained ethical approval from the Ethics Committee of the Jahrom University of Medical Sciences, Jahrom, Iran (No. IR.JUMS. REC.1397.154). All sampling processes was done during April 2019 to December 2019 from drug addicted individuals referred to the laboratories of the medical centers of Lar city in Fars Province, Iran. Regarding the criteria, confirmed addiction test and consent for participating were considered as inclusion criteria, and presence of immunodeficiency diseases were considered as exclusion criteria. G*Power software was applied to calculate the sample size in this case-control study. We used prevalence reference of $7.7 \%$ (IgG) [28], at a confidence intervals (CI) of $95 \%$, type I error $\alpha$ of 0.05 , and the power of the test $(1-\beta)$ of $90 \%$ to estimate the sample size. The calculation outcome was 135 individuals in each group, although 137 confirmed drug addicted individuals and 141 non-addicted individuals were employed for more accuracy. The control group were people who had no history of addiction. For a more accurate assessment, the age and sex of the control group were matched with the case group. An informed consent form as well as a standard questionnaire were designed and prepared for all participants. Each participant was interviewed orally by the interviewer. This questionnaire included the sociodemographic variables, and risk factors related to T. gondii infection. Afterwards, approximately $10 \mathrm{cc}$ of blood samples were gathered of each participant with and without EDTA. At first, a rapid HIV test was performed on samples from all participants, and if the result was negative, they entered the next stage. Then, the all samples were transported to the laboratory via the cold chain conditions. Blood samples were permitted to clot and centrifuged at $600 \times g$ for $10 \mathrm{~min}$ to extract the serum and buffy coats [30]. Finally, the separated serum (without EDTA) for serological assay and buffy coats (with EDTA) for PCR-based molecular assay were stored at $-20{ }^{\circ} \mathrm{C}$ until examination.

\section{Serological assay}

All serum samples were surveyed for anti-Toxoplasma IgG and IgM antibodies through a commercially available enzyme-linked immunosorbent assay (ELISA) kits (Pishtazteb Co, Iran) according to the manufacturer's protocol. This ELISA kits had the $100 \%$ sensitivity and 99\% specificity. Each run was accompanied by positive and negative controls. Anti-T. gondii IgG and IgM antibodies were estimated via dividing the sample optical density value by the cut-off calibrator value. Considering the kit protocol, when an IgG index or an IgM index was $\geq 1.1$, we considered that sample to be positive for IgG or IgM.

\section{Molecular assay}

The DNA was extracted from buffy coat samples through the CinnaPure-DNA extraction kit (CinnaGen Co., Tehran, Iran), as stated in the manufacturer's protocol. The concentration and quality of the DNA were determined using the NanoDrop spectrophotometer. We used two genes RE and GRA6 for molecular assessment. DNA extracted from the $T$. gondii tachyzoites standard RHstrain and deionized sterile water were used for each run as positive and negative controls, respectively. 
To detection of $T$. gondii, the PCR reaction was arranged in a $20 \mu \mathrm{L}$ total reaction volume comprising $10 \mu \mathrm{L}$ of Master mix, $5 \mu \mathrm{L}$ of DNA, $3 \mu \mathrm{L}$ deionized sterile water, and $1 \mu \mathrm{L}$ of each primer TOXO4 (forward: 5'-CGCTGCAGGGAGGAAGACGAAAGT TG-3') and TOXO5 (reverse: 5'-CGCTGCAGACAC AGTGCATCTGGATT- $3^{\prime}$ ) targeting the RE gene of T. gondii [31]. Thermal cycling profile was $94{ }^{\circ} \mathrm{C}$ for $5 \mathrm{~min}$, followed by 35 cycles of $30 \mathrm{~s}$ at $94{ }^{\circ} \mathrm{C}, 30 \mathrm{~s}$ at $63{ }^{\circ} \mathrm{C}$ and $30 \mathrm{~s}$ at $72{ }^{\circ} \mathrm{C}$ with a final step at $72{ }^{\circ} \mathrm{C}$ for $10 \mathrm{~min}$. The PCR amplification is characterized by the production of a $529 \mathrm{bp}$ band for the RE gene [31].

To identify the genotypes of T. gondii isolates, nested PCR were conducted by a set of specific primers targeting a GRA6 gene of $T$. gondii. At the first step, PCR was performed using GRA6-F1 (forward: 5'-ATTTGT GTTTCCGAGCAGGT-3') and GRA6-R1 (reverse: 5'-GCACCTTCGCTTGTGGTT-3'), which together amplify a 546-bp specific fragment [32]. Amplification was accomplished in final volume of $20 \mu \mathrm{L}$, comprising $10 \mu \mathrm{L}$ of Master mix, $5 \mu \mathrm{L}$ of DNA, $3 \mu \mathrm{L}$ deionized sterile water, and $1 \mu \mathrm{L}$ of each primer. The PCR amplification conditions were $94{ }^{\circ} \mathrm{C}$ for 5 min followed by 40 cycles of $94{ }^{\circ} \mathrm{C}$ for $30 \mathrm{~s}, 56{ }^{\circ} \mathrm{C}$ for $30 \mathrm{~s}$, and $72{ }^{\circ} \mathrm{C}$ for $30 \mathrm{~s}$, and final extension of $72^{\circ} \mathrm{C}$ for $10 \mathrm{~min}$ [32]. In the next step, a second PCR was performed using the forward primer GRA6-F2 (5'-TTTCCGAGCAGGTGA CCT-3') and the reverse primer GRA6-R2 (5'-TCG CCGAAGAGTTGACATAG-3') in order to amplify a 344-bp internal fragment used for genotype identification [32]. The second PCR reaction used $94{ }^{\circ} \mathrm{C}$ for $5 \mathrm{~min}$, followed by 30 cycles of $94{ }^{\circ} \mathrm{C}$ for $30 \mathrm{~s}, 59^{\circ} \mathrm{C}$ for $30 \mathrm{~s}$, and $72{ }^{\circ} \mathrm{C}$ for $30 \mathrm{~s}$, plus a final extension step at $72{ }^{\circ} \mathrm{C}$ for $10 \mathrm{~min}$ [32].

At the end, PCR products (both RE and GRA6 genes) were electrophoresed on a1.2\% agarose gel with $\mathrm{SYBR}^{\circledR}$ Safe stain and visualized using a UV Transilluminator.

\section{Sequencing}

PCR products of positive samples were sequenced using ABI 3730 Analyzers (Bioneer, Korea) and the results were compared with sequences available in the GenBank database by BLAST software.

\section{Statistical analysis}

To data the analysis, the Chi-square and Fisher's exact tests were performed using SPSS 18 software (SPSS, Chicago, IL, USA). The possible associations were estimated through odds ratios (OR) and $95 \%$ CI after adjustments. A $P$-value of $<0.05$ was considered statistically significant for differences.

\section{Results}

A total of 278 participants were involved in this study. Among these, 137 individuals were addicted with narcotic drugs (78.1\% male and $21.9 \%$ female) and 141 individuals were non-addicted ( $78 \%$ male and $22 \%$ female). Most addicts used opium (81.8\%) and the main route of use was inhalation (48.9\%). More sociodemographic characteristics and risk factors of $T$. gondii seroprevalence among addicted and non-addicted individuals are summarized in Table 1 and Additional file 1: Table S1, respectively. The seroprevalence of anti-T. gondii IgG antibody in drug addicted individuals 34.3\% (47/137) was higher than in non-addicted individuals $9.9 \%(14 / 141)$, a statistically significant difference was observed $(\mathrm{OR}=4.37$; 95\% $\mathrm{CI}=2.46-9.12 ; \mathrm{P}=0.001)$. Moreover, although the seroprevalence of $T$. gondii infection based on IgM antibody titer was $1.5 \%(2 / 137)$ in case group, no titer was observed in the control group, revealing no statistically significant association $(\mathrm{OR}=0.49 ; 95 \% \mathrm{CI}=0.43-0.55$; $\mathrm{P}=0.242$ ). As shown in Table 1 , there was only a statistically significant difference between age and anti- $T$. gondii IgG antibody in case group. Considering PCR assays with RE genomic target (Table 2), the prevalence of $T$. gondii infection was $5.1 \%(7 / 137)$ in case subjects and $3.5 \%(5 / 141)$ in the healthy control subjects, there was no statistically significant difference between case and control groups $(\mathrm{OR}=1.46 ; 95 \% \mathrm{CI}=0.45-4.73 ; \mathrm{P}=0.521)$. Molecular prevalence of $T$. gondii according to sociodemographic characteristics and risk factors for addicted and non-addicted individuals are presented in Table 2 and Additional file 2: Table S2, respectively. Then, genotyping was performed by the GRA6 genomic target on 12 positive molecular samples of case and control groups. In this regard, only 4 samples ( 2 samples from each case and control group) were genotyped. All four samples were genotype $\# 1$, which were submitted with accession numbers MW311068, MW311069, MW311070, and MW311071 in the GenBank.

\section{Discussion}

The prevalence of $T$. gondii infection and associated factors in drug addicted individuals are largely unknown. Consequently, the present case-control study attempted to determine the sero-molecular prevalence of $T$. gondii and the prevalence association with the sociodemographic characteristics and risk factors in addicted and non-addicted individuals in Lar, Iran. As the results of this study showed, exposure to T. gondii was higher in drug addicted individuals than in non-addicted individuals, which was significant for IgG. Addicted individuals may be more exposed to T. gondii infection due to poverty, poor health and nutritional condition. In Iran, one 


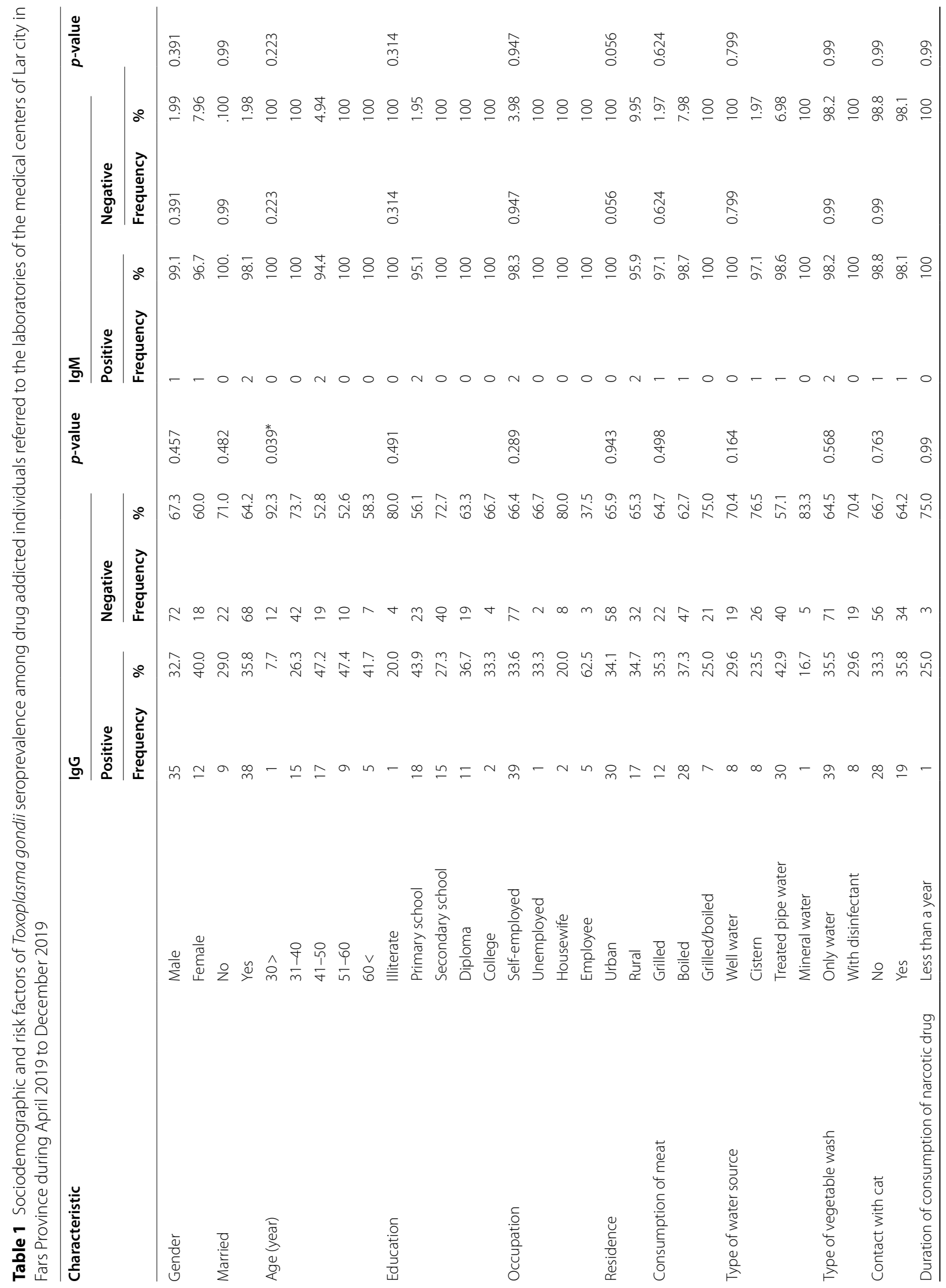




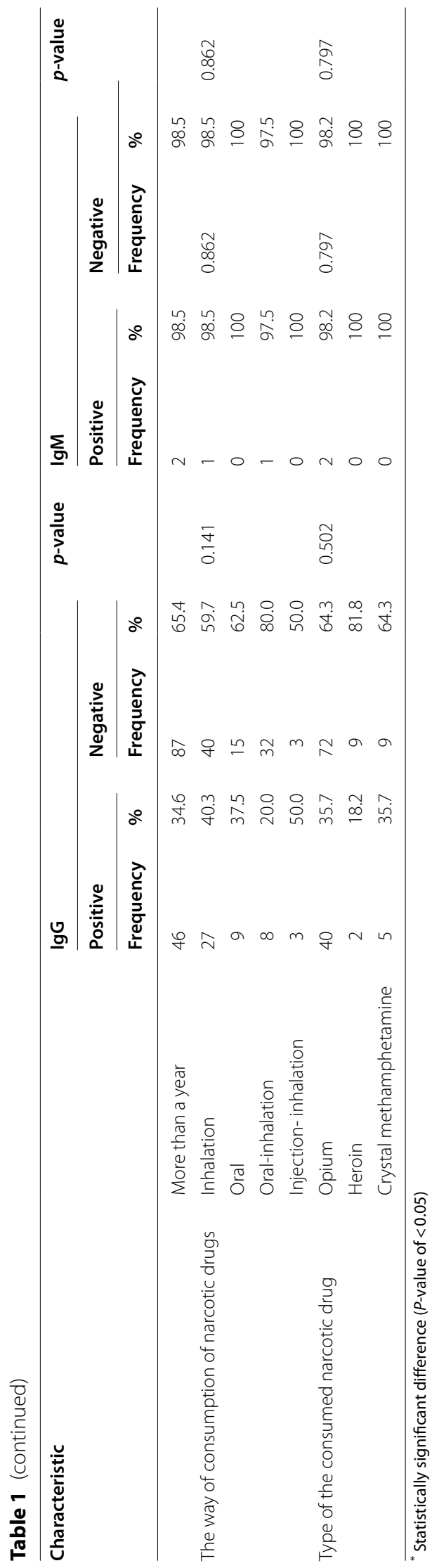


Table 2 Sociodemographic and risk factors of drug addicted individuals and molecular-prevalence of T. gondii infection referred to the laboratories of the medical centers of Lar city in Fars Province during April 2019 to December 2019

\begin{tabular}{|c|c|c|c|c|c|c|}
\hline \multirow[t]{3}{*}{ Characteristic } & & \multicolumn{4}{|c|}{ PCR with RE genomic target } & \multirow[t]{3}{*}{$P$-value } \\
\hline & & \multicolumn{2}{|l|}{ Positive } & \multicolumn{2}{|l|}{ Negative } & \\
\hline & & Frequency & $\%$ & Frequency & $\%$ & \\
\hline \multirow[t]{2}{*}{ Gender } & Male & 5 & 4.7 & 102 & 95.3 & 0.661 \\
\hline & Female & 2 & 6.7 & 28 & 93.3 & \\
\hline \multirow[t]{2}{*}{ Married } & No & 2 & 6.5 & 29 & 93.5 & 0.700 \\
\hline & Yes & 5 & 4.7 & 101 & 95.3 & \\
\hline \multirow[t]{5}{*}{ Age (year) } & $30>$ & 0 & 0 & 13 & 100 & 0.658 \\
\hline & $31-40$ & 4 & 7.0 & 53 & 93.0 & \\
\hline & $41-50$ & 2 & 6.5 & 34 & 94.4 & \\
\hline & $51-60$ & 0 & 0 & 19 & 100 & \\
\hline & $60<$ & 1 & 8.3 & 11 & 91.7 & \\
\hline \multirow[t]{5}{*}{ Education } & Illiterate & 0 & 0 & 5 & 100 & 0.876 \\
\hline & Primary school & 3 & 7.3 & 38 & 92.7 & \\
\hline & Secondary school & 3 & 5.5 & 52 & 94.5 & \\
\hline & Diploma & 1 & 3.3 & 29 & 96.7 & \\
\hline & College & 0 & 0 & 6 & 100 & \\
\hline \multirow[t]{4}{*}{ Occupation } & Self-employed & 7 & 6.0 & 109 & 94.0 & 0.721 \\
\hline & Unemployed & 0 & 0 & 3 & 100 & \\
\hline & Housewife & 0 & 0 & 10 & 100 & \\
\hline & Employee & 0 & 0 & 8 & 100 & \\
\hline \multirow[t]{2}{*}{ Residence } & Urban & 4 & 4.5 & 84 & 95.5 & 0.700 \\
\hline & Rural & 3 & 6.1 & 46 & 93.9 & \\
\hline \multirow[t]{3}{*}{ Consumption of meat } & Grilled & 4 & 11.8 & 30 & 88.2 & 0.125 \\
\hline & Boiled & 2 & 2.7 & 73 & 97.3 & \\
\hline & Grilled/boiled & 1 & 3.6 & 27 & 96.4 & \\
\hline \multirow[t]{4}{*}{ Type of water source } & Well water & 2 & 7.4 & 2 & 92.6 & \\
\hline & Cistern & 1 & 2.9 & 33 & 97.1 & \\
\hline & Treated pipe water & 4 & 5.7 & 66 & 94.3 & 0.801 \\
\hline & Mineral water & 0 & 0 & 6 & 100 & \\
\hline \multirow[t]{2}{*}{ Type of vegetable wash } & Only water & 7 & 6.4 & 103 & 93.6 & 0.178 \\
\hline & With disinfectant & 0 & 0 & 27 & 100 & \\
\hline \multirow[t]{2}{*}{ Contact with cat } & No & 5 & 6.0 & 79 & 94.0 & 0.706 \\
\hline & Yes & 2 & 3.8 & 51 & 96.2 & \\
\hline \multirow[t]{2}{*}{ Duration of consumption of narcotic drug } & Less than a year & 0 & 0 & 4 & 100 & 0.99 \\
\hline & More than a year & 7 & 5.3 & 126 & 94.7 & \\
\hline \multirow[t]{4}{*}{ The way of consumption of narcotic drugs } & Inhalation & 3 & 4.5 & 64 & 95.5 & 0.827 \\
\hline & Oral & 1 & 4.2 & 23 & 95.8 & \\
\hline & Oral-inhalation & 3 & 7.5 & 37 & 92.5 & \\
\hline & Injection-inhalation & 0 & 0 & 6 & 100 & \\
\hline \multirow[t]{3}{*}{ Type of the consumed narcotic drug } & Opium & 7 & 6.3 & 105 & 93.8 & 0.439 \\
\hline & Heroin & 0 & 0 & 11 & 100 & \\
\hline & Crystal methamphetamine & 0 & 0 & 14 & 100 & \\
\hline
\end{tabular}

study has been performed on the relationship between $T$. gondii infection and addicted women [29]; the methodology and results were different from our study. In their study, there was no significant relationship between the seroprevalence of anti- $T$. gondii IgG antibody in the case and control groups as well as molecular assay were not performed. However, this difference should be interpreted with caution because various factors such as 
methodology (study design), social, economic, geographical and demographic can play a intervening role in the difference prevalences [3]. In 2015, a meta-analysis of the relationship between $T$. gondii infection and addiction was performed with only four included articles [19]. The results of meta-analysis showed that there is a significant OR between the increased prevalence of $T$. gondii infection and addiction $(\mathrm{OR}=1.91 ; 95 \% \mathrm{CI}=1.49-2.44$; $\mathrm{P}=0.00001)$. However, in future research, it is suggested that more epidemiological studies be conducted on the prevalence of $T$. gondii in these high-risk group to gain in-depth insights into these relationships.

As shown in Tables and Additional file 1: Table S1 and Additional file 2: Table S2, we collected a wide range of sociodemographic characteristics and risk factors in both case and control groups, considering both serological and molecular techniques. Although only age was significantly associated with the anti-T. gondii IgG antibody in case group, other variables should not be ignored. In this regard, cats as the definitive hosts of $T$. gondii, play a key role in the transmission of sporulated oocysts to humans as well as polluting the environment [6]. A global meta-analysis study on contamination of soil with T. gondii oocysts was performed in different public places of the world [7]; in this regard, the estimated prevalences in Europe, South America, Asia and North America were $23 \%$ (95\% CI 4-65), 22\% (95\% CI 18-26), 15\% (95\% CI $0.06-33)$ and $8 \%$ (95\% CI $0.00-97)$, respectively. This indicates that most of the different regions in the world, especially public parks, are contaminated with $T$. gondii oocysts and the chance of acquiring the infection are high, especially in drug addicted individuals who often present in such environments. Due to the transmission of T. gondii through the blood, injecting drug users are more likely than other addicts to become infected due to the frequent use of contaminated syringes. However, injecting drug users participating in the present study had the lowest sample size compared to other addicts. Hence, a detailed assessment of the prevalence of T. gondii with higher sample size in injecting drug users is suggested.

In the present study, $1.5 \%$ of drug addicted individuals had IgM antibodies against $T$. gondii. It should be noted that the absence of IgM in people with anti- $T$. gondii IgG antibodies shows a chronic infection, but its presence does not necessarily indicate an acute infection [33]. Moreover, PCR results indicated that a relatively high number of cases $(5.1 \%)$ and controls (3.5\%) harbor circulating DNA of $T$. gondii. One of the most important reasons for the difference in prevalence between serological and molecular methods is the difference in sensitivity and specificity of these techniques [34]. Given that good PCR sensitivity is important for the detection of circulating DNA in people with chronic toxoplasmosis [34]. In the present study, all sequenced samples were from genotype \#1. Due to the fact that genotype \# 1 has more virulence capability than other genotypes (\#2 and \#3) and is often isolated in patients with immunodeficiency [32], it is suggested that more molecular epidemiology be done on addicts to better understand the distribution status of genotypes.

\section{Conclusions}

Our findings showed a high sero-molecular prevalence of T. gondii in addicted individuals in Iran. Such studies need to be done on a larger sample in other parts of the world and there is a need for health policymakers and researchers to establish enlightenment and prevention programs for these population at risk of infection.

\section{Supplementary Information}

The online version contains supplementary material available at https://doi. org/10.1186/s12879-021-06979-8.

Additional file 1: Table S1. Sociodemographic and risk factors of Toxoplasma gondii seroprevalence among non-addicted individuals referred to the laboratories of the medical centers of Lar city in Fars Province during April 2019 to December 2019.

Additional file 2: Table S2. Sociodemographic and risk factors of non-addicted individuals and molecular-prevalence of T. gondii infection referred to the laboratories of the medical centers of Lar city in Fars Province during April 2019 to December 2019.

\section{Acknowledgements}

The authors would like to thank all staff of Department of Medical Parasitology, Jahrom University of Medical Sciences.

\section{Authors' contributions}

HR and KS contributed to study design. HR and MS contributed to all parts of the study. ZKJ and ES contributed to study implementation. SS collaborated in the analysis and interpretation of data. AT collaborated in the manuscript writing and revision. All the authors commented on the drafts of the manuscript and approved the final version of the article. All authors read and approved the final manuscript.

\section{Funding}

This study was supported by Jahrom University of Medical Sciences, Iran, Grant Number: 1397.154 was awarded to Hassan Rezanezhad. This funding was used to provide the materials for this study.

Availability of data and materials

All data is available in the text of the manuscript, Tables, and Additional files.

\section{Declarations}

Ethics approval and consent to participate

This study was approved by Jahrom University of Medical Sciences Ethics Committee (ethical approval ID: IR.JUMS.REC.1397.154). All methods were carried out in accordance with relevant guidelines and regulations according to the Helsinki declaration. Informed consent was obtained from all participants or, if participants were under 18 , from a parent and/or legal guardians.

Consent for publication

Not applicable. 


\section{Competing interests}

The authors declare that they have no competing interests.

\section{Author details}

${ }^{1}$ Department of Medical Parasitology and Mycology, School of Medicine, Jahrom University of Medical Sciences, Jahrom, Iran. ${ }^{2}$ Zoonoses Research Center, Jahrom University of Medical Sciences, Jahrom, Iran. ${ }^{3}$ Department of Medical Entomology and Vector Control, School of Health, Shiraz University of Medical Sciences, Shiraz, Iran.

Received: 11 Auqust 2021 Accepted: 14 December 2021

Published online: 04 January 2022

\section{References}

1. Dubey JP. The history of Toxoplasma gondii-the first 100 years. J Eukaryot Microbiol. 2008;55(6):467-75.

2. Gebremedhin EZ, Tadesse G. A meta-analysis of the prevalence of Toxoplasma gondii in animals and humans in Ethiopia. Parasit Vectors. 2015;8(1):1-9.

3. Rostami A, Riahi SM, Contopoulos-loannidis DG, Gamble HR, Fakhri Y, Shiadeh MN, Foroutan M, Behniafar H, Taghipour A, Maldonado YA. Acute Toxoplasma infection in pregnant women worldwide: a systematic review and meta-analysis. PLoS Negl Trop Dis. 2019;13(10):e0007807.

4. Hill DE, Dubey JP. Toxoplasma gondii. In: Foodborne parasites. edn. Springer; 2018. p 119-138.

5. Dubey J. History of the discovery of the life cycle of Toxoplasma gondii. Int J Parasitol. 2009;39(8):877-82.

6. Hatam-Nahavandi K, Calero-Bernal R, Rahimi MT, Pagheh AS, Zarean M, Dezhkam A, Ahmadpour E. Toxoplasma gondii infection in domestic and wild felids as public health concerns: a systematic review and metaanalysis. Sci Rep. 2021;11(1):1-11.

7. Maleki B, Ahmadi N, Olfatifar M, Gorgipour M, Taghipour A, Abdoli A, Khorshidi A, Foroutan M, Mirzapour A. Toxoplasma oocysts in the soil of public places worldwide: a systematic review and meta-analysis. Trans $R$ Soc Trop Med Hyg. 2021;115(5):471-81.

8. Ducrocq J, Simon A, Lemire M, De Serres G, Lévesque B. Exposure to Toxoplasma gondii through consumption of raw or undercooked meat: a systematic review and meta-analysis. Vector-Borne Zoonotic Dis. 2021;21(1):40-9.

9. Shapiro K, Bahia-Oliveira L, Dixon B, Dumètre A, de Wit LA, VanWormer E, Villena I. Environmental transmission of Toxoplasma gondii: oocysts in water, soil and food. Food Waterborne Parasitol. 2019;15:e00049.

10. Raissi V, Taghipour A, Navi Z, Etemadi S, Sohrabi Z, Sohrabi N, Getso M, Shamsaei S, Fasihi Karami M, Raiesi O. Seroprevalence of Toxoplasma gondii and Toxocara spp. infections among pregnant women with and without previous abortions in the west of Iran. J Obstet Gynaecol Res. 2020;46(3):382-8.

11. Dard C, Marty P, Brenier-Pinchart M-P, Garnaud C, Fricker-Hidalgo $H_{4}$ Pelloux H, Pomares C. Management of toxoplasmosis in transplant recipients: an update. Expert Rev Anti Infect Ther. 2018;16(6):447-60.

12. Yousefi E, Foroutan M, Salehi R, Khademvatan S. Detection of acute and chronic toxoplasmosis amongst multi-transfused thalassemia patients in southwest of Iran. J Acute Dis. 2017;6(3):120.

13. Khan K, Khan W. Congenital toxoplasmosis: an overview of the neurological and ocular manifestations. Parasitol Int. 2018;67(6):715-21.

14. Pereira-Chioccola VL, Vidal JE, Su C. Toxoplasma gondii infection and cerebral toxoplasmosis in HIV-infected patients. Future Microbiol. 2009;4(10):1363-79.

15. Abdoli A, Taghipour A, Pirestani M, Jahromi MAM, Roustazadeh A, Mir H, Ardakani HM, Kenarkoohi A, Falahi S, Karimi M. Infections, inflammation, and risk of neuropsychiatric disorders: the neglected role of "co-infection." Heliyon. 2020;6(12):e05645.

16. Nayeri T, Sarvi S, Moosazadeh M, Hosseininejad Z, Sharif M, Amouei A, Daryani A. Relationship between toxoplasmosis and autism: a systematic review and meta-analysis. Microb Pathogen. 2020;2020:104434.

17. Amouei A, Moosazadeh M, Nayeri Chegeni T, Sarvi S, Mizani A, Pourasghar M, Hosseini Teshnizi S, Hosseininejad Z, Dodangeh S, Pagheh A. Evolutionary puzzle of Toxoplasma gondii with suicidal ideation and suicide attempts: an updated systematic review and meta-analysis. Transbound Emerg Dis. 2020;67(5):1847-60.

18. Gohardehi S, Sharif M, Sarvi S, Moosazadeh M, Alizadeh-Navaei R, Hosseini SA, Amouei A, Pagheh A, Sadeghi M, Daryani A. The potential risk of toxoplasmosis for traffic accidents: a systematic review and meta-analysis. Exp Parasitol. 2018;191:19-24.

19. Sutterland A, Fond G, Kuin A, Koeter M, Lutter R, Van Gool T, Yolken R, Szoke A, Leboyer M, De Haan L. Beyond the association. Toxoplasma gondii in schizophrenia, bipolar disorder, and addiction: systematic review and meta-analysis. Acta Psychiatr Scand. 2015;132(3):161-79.

20. SARDAR SI. Drug Abuse: Global vs South Asian trends with special reference to India and Pakistan. Institute of Regional Studies, Islamabad 2016:3.

21. Malik A, Sarfaraz SF. Origin and development of drug addiction in South Asia with special reference to Pakistan. Pak J Comm Soc Sci (PJCSS). 2011;5(1):155-65.

22. Ayatollahi-Mousavi SA, Asadikaram G, Nakhaee N, Izadi A, Keikha N. The effects of opium addiction on the immune system function in patients with fungal infection. Addict Health. 2016;8(4):218.

23. Saurer TB, Ijames SG, Carrigan KA, Lysle DT. Neuroimmune mechanisms of opioid-mediated conditioned immunomodulation. Brain Behav Immun. 2008;22(1):89-97.

24. Friedman $H$, Pross $S$, Klein TW. Addictive drugs and their relationship with infectious deseases. FEMS Immunol Med Microbiol. 2006;47(3):330-42.

25. Daryani A, Sarvi S, Aarabi M, Mizani A, Ahmadpour E, Shokri A, Rahimi M-T, Sharif M. Seroprevalence of Toxoplasma gondii in the Iranian general population: a systematic review and meta-analysis. Acta Trop. 2014;137:185-94.

26. Foroutan-Rad M, Khademvatan S, Majidiani H, Aryamand S, Rahim F, Malehi AS. Seroprevalence of Toxoplasma gondii in the Iranian pregnant women: a systematic review and meta-analysis. Acta Trop. 2016;158:160-9.

27. Ahmadpour E, Daryani A, Sharif M, Sarvi S, Aarabi M, Mizani A, Rahimi MT, Shokri A. Toxoplasmosis in immunocompromised patients in Iran: a systematic review and meta-analysis. J Infect Dev Countries. 2014;8(12):1503-10.

28. Buchy P, Follezou J, Lien T, An T, Tram L, Tri D, Cuong N, Glaziou P, Chien B. Serological study of toxoplasmosis in Vietnam in a population of drug users (Ho Chi Minh city) and pregnant women (Nha Trang). Bull Soc Pathol Exotique (1990). 2003;96(1):46-7.

29. Dehghan Haghighi J, Hosseini A, Shafiei R, Mehravaran A, Alijani E, Mirahmadi $\mathrm{H}$. Evaluation of Toxoplasma gondii antibodies in addicted and non-addicted women in Zahedan, Southeast of Iran. Int J High Risk Behav Addict. 2020;9(3).

30. Brenier-Pinchart M-P, Capderou E, Bertini R-L, Bailly S, Fricker-Hidalgo H, Varlet-Marie E, Murat J-B, Sterkers Y, Touafek F, Bastien P. Molecular diagnosis of toxoplasmosis: value of the buffy coat for the detection of circulating Toxoplasma gondii. Diagn Microbiol Infect Dis. 2015;82(4):289-91.

31. Homan W, Vercammen M, De Braekeleer J, Verschueren H. Identification of a 200-to 300-fold repetitive 529 bp DNA fragment in Toxoplasma gondii, and its use for diagnostic and quantitative PCR. Int J Parasitol. 2000;30(1):69-75.

32. Khan A, Su C, German M, Storch G, Clifford D, Sibley LD. Genotyping of Toxoplasma gondii strains from immunocompromised patients reveals high prevalence of type I strains. J Clin Microbiol. 2005;43(12):5881-7.

33. Alvarado-Esquivel C, Mercado-Suarez MF, Rodríguez-Briones A, FalladTorres L, Ayala-Ayala JO, Nevarez-Piedra LJ, Duran-Morales E, Estrada-Martínez S, Liesenfeld O, Márquez-Conde JÁ. Seroepidemiology of infection with Toxoplasma gondii in healthy blood donors of Durango, Mexico. BMC Infect Dis. 2007;7(1):1-7.

34. Fallahi S, Rostami A, Birjandi M, Zebardast N, Kheirandish F, Spotin A. Parkinson's disease and Toxoplasma gondii infection: sero-molecular assess the possible link among patients. Acta Trop. 2017;173:97-101.

\section{Publisher's Note}

Springer Nature remains neutral with regard to jurisdictional claims in published maps and institutional affiliations. 